\title{
Survey and Analysis on the Satisfaction of Graduates Majoring in Biomedical Engineering With Internship
}

\author{
Lina $\mathrm{Wu}^{1, *}$, Chunjing Zhang ${ }^{1}$, Tai Yang $^{1}$, Chunqiang Zhang ${ }^{1}$ \\ ${ }^{1}$ College of Medical Technology, Qiqihar Medical University, Heilongjiang, 161000, China \\ *Corresponding Author Email:261102958@qq.com
}

\begin{abstract}
In order to strengthen the quality control and dynamic management of the teaching base for clinical practice of biomedical engineering, 89 questionnaires were designed and distributed to find out graduates' satisfaction with teaching bases of clinical practice, which surveyed the satisfaction with internship bases in and outside the province in terms of internship organization and management, tutors, internship effect and conditions. This paper analyzes and summarizes the results of this survey, explores the problems in the construction of practice teaching base and provides complete suggestions and measures in accordance with related teaching system and experience in order to provide reference for the reform and development of the teaching in institutions of high learning.
\end{abstract}

Keywords: biomedical engineering major, practice teaching, teaching base, satisfaction rate

\section{INTRODUCTION}

Facing the new situation of college enrolment expansion, how medical education, especially clinical education, deal with the opportunities and challenges and how to strengthen the standardized management of clinical teaching to ensure the quality of clinical teaching are important tasks facing medical colleges and universities. Graduation internship is an important part of undergraduate teaching, a vital means to test the teaching effect, and also an essential practical stage of talent training.[1] For a long time, our college has attached great importance to the internship, which has been included into the teaching management category from the selection of its internship base, the improvement of its conditions, the evaluation of tutors and the survey of students' satisfaction with the practice base. Therefore, for a long time, medical universities have attached great importance to medical graduate internship and the construction of practical teaching base. From the teachers' training in teaching base for the clinical practice to the improvement of internship conditions, as well as the students' satisfaction with the practical teaching base, etc., they have been brought into the teaching management category in higher medical colleges[2]. Take the major of biomedical engineering of Qiqihar Medical College as an example; it has strengthened the contact and communication with domestic hospitals to ensure that students can have sufficient educational and teaching resources to meet their internship. In addition, it strengthens its management of clinical practice teaching by incentivizing non-affiliated hospitals, teaching hospitals, internship bases and tutors in teaching bases. In order to optimize and improve the internship situation for this major, a questionnaire survey was conducted among the interns from the 2016 class to the
2020 class so as to find and solve problems related to internship.

\section{OBJECT AND METHOD}

\subsection{Object}

A total of 117 graduates majoring in biomedical engineering have accepted the questionnaires and 89 questionnaires have been collected. The questionnaire mainly involves the first 11 graduates of 2016 class, with participation rate of $52.38 \%(11 / 21) .17$ students of 2017class, with participation rate of $85.00 \%$ (17/20); 17 students of 2018 class, with participation rate of $70.83 \%$ (17/24); 20 students of 2019 class, $71.43 \%$ (20/28); 24 students of 2020 class, $100 \%$ (24/24).

\subsection{Method}

The closed questions and open questions were presented in the form of self-filled questionnaire. The questionnaire will be sent to all teaching bases and interns by the Academic Affairs Department of the College of Medical Technology. The questionnaires will be collected from all classes and then the feedback will be given to the department.

\subsection{Investigation Contents}

The main content of the student questionnaire includes the evaluation of the organization and management of the internship, tutors, the effect and the conditions of the internship. 


\subsection{Statistical Analysis}

Epi Data 3.0 software is used for Data entry and error detection, and SPSS 17.0 software is used for Data sorting and integration.

\section{RESULTS AND ANALYSIS}

\subsection{Students' satisfaction with the organization and management of internship}

A total of 89 valid questionnaires were collected in the form of "questionnaire star" for the graduates. Most of the graduates were satisfied with the overall internship, accounting for $85.4 \%$.

Table 1. Students' satisfaction with the effect of internship

\begin{tabular}{|l|c|c|c|c|c|}
\hline \multirow{2}{*}{$\begin{array}{c}\text { Graduates } \\
\text { Grade }\end{array}$} & \multicolumn{4}{|c|}{ Satisfaction rate (\%) } & \multirow{2}{*}{ Sum } \\
\cline { 2 - 5 } & Very satisfied & Satisfied & Not satisfied & $\begin{array}{c}\text { Not satisfied } \\
\text { at all }\end{array}$ & \\
\hline $\mathbf{2 0 1 6}$ & $7(63.6)$ & $2(18.2)$ & $2(18.2)$ & $0(0)$ & $11(100)$ \\
\hline $\mathbf{2 0 1 7}$ & $10(58.8)$ & $4(23.5)$ & $2(11.8)$ & $1(5.9)$ & $17(100)$ \\
\hline $\mathbf{2 0 1 8}$ & $12(70.6)$ & $3(17.6)$ & $2(11.8)$ & $0(0)$ & $17(100)$ \\
\hline $\mathbf{2 0 1 9}$ & $15(75)$ & $3(15)$ & $2(10)$ & $0(0)$ & $20(100)$ \\
\hline $\mathbf{2 0 2 0}$ & $18(75)$ & $2(8.3)$ & $4(16.7)$ & $0(0)$ & $24(100)$ \\
\hline
\end{tabular}

Through the open questions in the questionnaire, students' opinions and suggestions on the organization and management of the internship mainly include: (1) short period of internship; (2) It is suggested to consider students' own willingness to adjust the internship time in each department; (3) The time conflict between internship and postgraduate entrance examination affects the effect of internship.

\subsection{Students' satisfaction with tutors}

In the evaluation of students' satisfaction with their tutors, satisfaction rate is relatively high in three aspects, namely, the teacher's conscientiousness and responsibility in the teaching process, the high level of professional knowledge, and the ability to expound the content of internship clearly.

Table 2. Graduates' satisfaction with tutors (N \%)

\begin{tabular}{|l|l|l|l|l|}
\hline \multirow{2}{*}{ Teachers' ability } & \multicolumn{4}{|c|}{ Level of Need } \\
\cline { 2 - 5 } & Very Good & Good & Regular & Poor \\
\hline Are they responsible in tutoring & $66(74.16)$ & $15(16.85)$ & $6(6.74)$ & $2(2.25)$ \\
\hline How is their professional knowledge & $51(57.3)$ & $17(19.1)$ & $15(16.85)$ & $6(6.74)$ \\
\hline How is their technical operation & $70(78.65)$ & $11(12.36)$ & $8(8.99)$ & $0(0.0)$ \\
\hline How is their ability in imparting knowledge & $44(49.44)$ & $27(30.34)$ & $14(15.73)$ & $4(4.49)$ \\
\hline Their professional ability & $41(46.07)$ & $42(47.19)$ & $4(4.49)$ & $2(2.25)$ \\
\hline Their personal quality & $48(53.93)$ & $22(24.72)$ & $12(13.48)$ & $7(7.87)$ \\
\hline
\end{tabular}

The students' opinions and suggestions to the teachers are as follows: (1) communication between teachers and students should increase; (2) teaching forms should be diversified; (3) theoretical knowledge should be taught in a centralized way to reduce the repetition of teaching.

\subsection{Students' satisfaction with effect of internship}

In terms of the internship effect, students believe that there are three major gains, one is to improve the professional practice ability, the second is to strengthen the establishment of professional ethics, and the third is to improve the level of professional knowledge in different degrees (see table 3 ) 
Table 3. Graduates' satisfaction with the effect of internship (N \%)

\begin{tabular}{|l|l|l|l|c|}
\hline \multirow{2}{*}{ Effect of internship } & \multicolumn{3}{|c|}{ Level of Need } \\
\cline { 2 - 5 } & Very good & Good & Regular & Poor \\
\hline The improvement of professional knowledge & $77(86.52)$ & $11(12.36)$ & $1(1.12)$ & $0(0.0)$ \\
\hline The improvement of your skill level & $69(77.53)$ & $16(17.98)$ & $4(4.49)$ & $0(0.0)$ \\
\hline The establishment of their own work ethic & $61(68.54)$ & $18(20.22)$ & $10(11.24)$ & $0(0.0)$ \\
\hline
\end{tabular}

Through the open questions in the questionnaire, the main gains of students in other aspects include: (1) understanding the latest trend of the subject; (2) improving interpersonal skills.

2.4 Students' satisfaction with the condition of internship Office environment: Most students think that bases can provide a good practice and office environment. But this condition is limited by the objective situation of the teaching bases. Some students are temporarily arranged for studying in the library or laboratory due to the shortage of office space.

Accommodation conditions: most students think accommodation conditions in bases are not bad. However, the bases are far from the college and the price for meals in some bases is relatively high, hence, some students hope that colleges or bases can provide accommodation and some dining subsidies.

\section{PROBLEMS}

\subsection{Clinical practice teaching needs to be strengthened}

Compared with clinical skills, our college graduates have a relatively high evaluation of their own theoretical level, which reflects the problems in the teaching process of emphasizing basic medical theory teaching and neglecting clinical practice teaching. In the teaching process, we should develop internship platform, increase practice teaching hours, and highlight the importance of practice teaching, change the students' idea of valuing theory and neglecting skills, improve the proportion of practical examination results, and arouse the students' initiative and enthusiasm to participate in practical teaching.

\subsection{The teaching methods need to be changed}

Many courses are offered in engineering majors in medical colleges with obscure contents. It is difficult for students to fully meet the needs of future work with the knowledge and skills learned during the internship. The traditional "passive learning" teaching mode can no longer cultivate talents with high and excellent quality. This requires colleges to continuously deepen the reform of teaching methods, make classroom teaching content more practical and easy to understand, and shorten the distance between theory and practice.

\subsection{Medical humanistic quality needs to be improved}

Our college has put forward higher requirements on the cultivation of graduates' medical humanistic quality during their study in the college, which reflects the college emphasizes professional quality education and neglects medical humanistic education in teaching. Medical science is a discipline combining natural science with humanities and social science. Professional value, attitude, behavior and ethics have become the core competence and basic quality requirements for medical students. Therefore, medical colleges and universities should strengthen medical humanistic education to realize synchronous cultivation of medical humanistic quality, medical professional knowledge and clinical practical skills.

\subsection{Poor scientific research ability}

Graduates think that their ability in scientific research and innovation is relatively weak, which reflects that cultivating of scientific research ability is generally missing in the training of talents. An outstanding graduate must pay equal attention to clinical practice and scientific research, so as to realize the great development of medicine with" scientific research assisted by clinic and clinical practice applied in scientific research ". Therefore, medical colleges should strengthen the cultivation of students' scientific research ability according to their professional characteristics and academic resources.

\section{SUGGESTIONS AND MEASURES}

\subsection{Integration of clinical practice teaching and basic medicine teaching}

Medical students can transform theoretical knowledge into practical skills through clinical practice on the basis of mastering theory. In the process of clinical practice, they can feel the gap between clinical work and classroom teaching, improve the enthusiasm of learning theoretical knowledge, and lay a solid foundation for clinical practice[3]. It is necessary to give full play to the teaching functions of affiliated hospitals of medical colleges and integrate its high-quality teachers and teaching resources, 
so that students can master the basic clinical operation proficiently and be familiar with the relevant procedures of routine diagnosis and treatment in the hospital during their study at school, thus improving their practical ability.

\subsection{Deepening the reform of teaching methods}

The teaching reform and research work are carried out centering on the transformation of training mode, curriculum construction, reform of teaching methods and means, reform of examination and other links in personnel training. It should give full play to the guiding role of resource allocation, promote various teaching reform projects, and institutionalize and regularize undergraduate reform. In the reform of basic medical teaching, it is necessary to strengthen the application of various teaching methods, such as case-based teaching method, problem-based teaching method, bedside teaching method, clinical skill simulation teaching method, mixed teaching method and so on which can be used in basic courses and clinical teaching[4]. In addition to giving lectures, it advocates heuristic learning and discussion-based learning, implements student-centered teaching such as problems-based teaching, group instruction teaching, case-based teaching and mixed teaching, and cultivates students' ability to acquire knowledge, clinical diagnosis and treatment thinking and problem solving ability [5].

\subsection{Strengthening medical humanities education}

We should strengthen medical humanities education while cultivating students' professional quality and clinical skills. What's more, we should offer medical ethics and the humanities curricula, enrich the content of medical humanities education, form the curriculum system characterized by "organ system as the main line while emphasizing knowledge, ability and quality education on the basis of curriculum integration and improving students' comprehensive ability as the core", enhance students' medical ethics accomplishment, clinical practice ability and self-study ability and innovation ability, train medical workers with lofty ideals, moral character and goodness[6] It should give full play to the advantages of comprehensive disciplines of universities and the leading role of corresponding universities bearing the responsibility of assistance, integrate the humanistic education resources of the university and affiliated hospitals, form the resultant force among medical humanistic education, research and practice, and improve the level of medical humanistic education[7].

\subsection{Cultivating students' ability in scientific research and innovation}

Through academic lectures, salons and other activities, colleges can help students understand cutting-edge medical theories and research trends, broaden their horizons and knowledge, and cultivate their interest in scientific research. It should open the laboratory, purchase the corresponding experimental equipment, equip with guidance teachers with the relevant research field and improve students' conditions for scientific and technological innovation. In addition, it should encourage students to actively participate in scientific research and innovation projects and make them master necessary scientific research skills.

\section{CONCLUSION}

In terms of their satisfaction with the organization and management of internships, students and teachers generally have low satisfaction with the arrangement of internship time, mainly because they think that the on-site internship time is too short. The consequence is that students are unable to deeply study the professional knowledge of various disciplines with only learning some simple knowledge and most students' subjective initiative and creativity are limited by short internship period and overemphasis of the leading role of tutors, which is not conducive to the cultivation and improvement of students' individual ability. We need to deeply consider this problem in the future internship arrangement. It should extend the internship time appropriately without affecting the school's teaching plan and try to avoid the time for students to prepare for the postgraduate entrance examination. In addition, in this survey, students reflect that it should consider their own willingness in internship arrangement and grouping. In view of this problem, we should carry out our work according to the setup of each department and actual work progress in each teaching base.

Students reflect that the internship arrangement is not appropriated in this survey. The reasons are that on one hand, due to the heavy burden in their regular administrative tasks, teaching and research programs, tutors' teaching work isn't arranged tightly; on the other hand, students lack initiative in learning. They do not seize fragmented learning opportunities and do not take the initiative to ask for advice when they encounter problems. Students are often passive learners in colleges while teachers often cram knowledge to them. However, internship is a heuristic teaching method, which requires students to give full play to their subjective initiative and discover their weaknesses and deficiencies in their knowledge system in order to improve their comprehensive ability. Therefore, it is especially important for students to learn, think and ask for advice actively in their study and internship, which puts forward higher requirements for students' internship. Only with teachers' continuous guidance in internship can students be cultivated such capacity.

From the perspective of students' satisfaction with tutors, it is suggested that teachers in internship bases should pay attention to their language and behaviors in the teaching process, both in terms of professional quality and working 
ability, and stimulate students' love for their major through words and deeds, so that students will have a strong sense of identity for their future career. In addition, the survey suggests that teachers should fully prepare lessons before tutoring, grasp the requirements of the syllabus and teaching content, and provide students with as many practical opportunities as possible. What's more, with the limited practice opportunities, it is suggested that we should make full use of practice teaching materials for case teaching in each base, so as to gradually realize the guiding role of teachers in imparting knowledge and methods.

\section{ACKNOWLEDGMENT}

The Project by Higher Education Teaching Reform of Heilongjiang Province (SJGY20190754)

\section{REFERENCES}

[1] Ma Chongyang, "Investigation and Analysis on the quality of clinical medicine graduates of Zhejiang Medical University" J. Northwest Medical Education. 2014, 22(6):1107-1109. (In Chinese)

[2] Ding Yanxia, "Follow up investigation and Analysis on the quality of graduates from Medical College of
Zhengzhou University” J. Higher Medical Education. 2011(9):18-19. (In Chinese)

[3] Wang Yunpeng, "Investigation and analysis report on the quality of graduates of a Medical University" J. Higher Medical Education. 2012(10):53-54. (In Chinese)

[4] Yi Luqian, "Research and preliminary practice of optimizing construction mode of off campus clinical teaching base" J. Higher Medical Education. 2014, 6:36-37. (In Chinese)

[5] Ren Bailing, "Cause analysis and Countermeasures of the decline of clinical practice teaching quality" J. Western Medicine. 2018, 16:270-271. (In Chinese)

[6] Qiu Junhua, “Analysis of influencing factors of practice quality of preventive medicine specialty and Countermeasures" J. Journal of Gannan Medical College. 2016, 33 (5) 682-683. (In Chinese)

[7] Chen Jihua, "Teaching experience in preventive medicine production practice" J. A guide to seeking knowledge. 2014 (7):100. (In Chinese) 